\title{
Toll-Like Receptor 2 Induced Senescence in Intervertebral Disc Cells of Patients with Back Pain can be Attenuated by o-Vanilin
}

\section{Matthew Mannarino}

McGill University Faculty of Medicine https://orcid.org/0000-0001-7086-7396

Hosni Cherif

McGill University Faculty of Medicine

Li Li

McGill University Faculty of Medicine

Kai Sheng

Research Institute of the McGill University Health Centre

Oded Rabau

McGill University Faculty of Medicine

\section{Peter Jarzem}

Research Institute of the McGill University Health Centre

\section{Michael $\mathrm{H}$. Weber}

Research Institute of the McGill University Health Centre

Jean A. Ouellet

Research Institute of the McGill University Health Centre

Lisbet Haglund ( $\square$ lisbet.haglund@mcgill.ca )

McGill University https://orcid.org/0000-0002-1288-2149

\section{Research article}

Keywords: intervertebral disc, senescence, toll-like receptor 2, o-Vanillin, degeneration, inflammation, senolytics, back pain

Posted Date: January 25th, 2021

DOI: https://doi.org/10.21203/rs.3.rs-60252/v2

License: (c) (i) This work is licensed under a Creative Commons Attribution 4.0 International License.

Read Full License 
Version of Record: A version of this preprint was published at Arthritis Research \& Therapy on April 16th, 2021. See the published version at https://doi.org/10.1186/s13075-021-02504-z. 


\section{Abstract}

Backgroud: There are an increased level of senescent cells and Toll Like Receptor-1 -2 -4 and -6 (TLR) expression in degenerating intervertebral discs (IVDs) from back pain patients. However, it is currently not known if the increase in expression of TLRs is related to the senescent cells or if it is a more general increase on all cells. It is also not known if TLR activation in IVD cells will induce cell senescence.

Methods: Cells from non-degenerate human IVD were obtained from spine donors and cells from degenerate IVDs came from patients undergoing surgery for low back pain. Gene expression of TLR$1,2,4,6$, senescence and senescence-associated secretory phenotype (SASP) markers was evaluated by RT-qPCR in isolated cells. Matrix synthesis was verified with safranin-O staining and Dimethyl-Methylene Blue Assay (DMMB) confirmed proteoglycan content. Protein expression of $\mathrm{p} 16^{1 N K 4 a}$, SASP factors and TLR-2 was evaluated by immunocytochemistry (ICC) and/or by enzyme-linked immunosorbent assay (ELISA).

Results: An increase in senescent cells was found following 48h induction with a TLR-2/6 agonist in cells from both non-degenerate and degenerating human IVDs. Higher levels of SASP factors, TLR-2 gene expression and protein expression was found following $48 \mathrm{~h}$ induction with TLR-2/ 6 agonist. Treatment with o-Vanillin reduced the number of senescent cells, and increased matrix synthesis in IVD cells from back pain patients. Treatment with o-Vanillin after induction with TLR-2/6 agonist reduced gene and protein expression of SASP factors and TLR-2. Co-localized staining of $\mathrm{p} 16^{\text {INK4a }}$ and TLR-2 demonstrated that senescent cells have a high TLR-2 expression.

Conclusions: Taken together our data demonstrate that activation of TLR-2/ 6 induce senescence and increase TLR-2 and SASP expression in cells from non-degenerate IVDs of organ donors without degeneration and backpain and in cells from degenerating human IVD of patients with disc degeneration and backpain. The senescent cells showed high TLR-2 expression suggesting a link between TLR activation and cell senescence in human IVD cells. The reduction in senescence, SASP and TLR-2 expression suggest o-Vanillin as a potential disease modifying drug for patients with disc degeneration and backpain.

\section{Background}

Low back pain is a global health problem that has been associated with intervertebral disc (IVD) degeneration (1-3). It is experienced by approximately $80 \%$ of individuals at some time in their lifespan (4). Globally back pain is the number one cause of years lived with disability (4). The personal costs in reduced quality of life, as well as the economic cost to healthcare systems are enormous and exceeds $\$ 100$ billion per year in the US alone (5). Current evidence suggests that changes in the biomechanical properties of degenerating discs is associated with matrix fragmentation, inflammation and pain (6). However, it is less clear how pain and degeneration are initiated and how they could be prevented. There is a growing interest in the accumulation of senescent cells in degenerating and ageing 
tissues. These senescent cells are viable cells that can no longer divide. Senescence can be induced due to the successive shortening of telomere length during replicative cycles (7). In addition, the number of senescent cells can also be increased by stressors including DNA damaging agents, oxidative stress, mitochondrial dysfunction, load induced injury and disruption of epigenetic regulation. This phenomenon is called stress-induced premature senescence and it is believed to be linked to the accumulation of senescent cell in degenerate IVDs $(8,9)$. Furthermore, senescent cells release an array of inflammatory cytokines, chemokines, and proteases known collectively as the senescence-associated secretory phenotype (SASP) (10).

All senescent cells have common features, but they also possess distinct characteristics which are linked to the different types of senescence (replicative \& stress-induced senescence), cell and tissue types (11, 12). The inflammatory environment triggered by senescent cells prevents adjacent cells from maintaining tissue homeostasis $(13,14)$ and it is proposed to induce senescence in a paracrine manner thus exacerbating tissue deterioration (15). Currently, conventional pharmacotherapy for IVD degeneration has both a high cost and many potential negative side effects, which has stimulated the interest in natural plant-based products with anti-inflammatory and regenerative properties, as an alternative or adjunct to conventional therapy. These products are being investigated for potential efficacy in a wide range of disorders with an inflammatory component, including osteoarthritis and cancer $(16,17)$. Recently, there have been a number of synthetic and natural drugs described with a specific mode of action to target and remove senescent cells, referred to as senolytics $(18,19)$.

Senolytics target many different pathways such as interfering with the dependence receptors, which promote apoptosis when unoccupied by ligands. Targeting and blocking signaling pathways involved in cell survival regulation interferes with mitochondrial-dependent apoptosis (20). One natural senolytic, oVanillin, a metabolite of a Curcumin, has anti-inflammatory properties and potent senolytic activity with a very wide non-toxic window for non-senescent IVD cells (18). Treatment with o-Vanillin has previously been shown to increase proteoglycan production of nucleus pulposus (NP) cells pellet culture (18). Furthermore, o-Vanillin interacts with a variety of cell surface receptors including Toll-like Receptors (TLR), Vanilloid, Chemokine and Opioid receptors and could broadly reduce the levels of pro-inflammatory mediators and reduce matrix degradation, possibly preventing IVD degeneration $(21,22)$.

In human IVD's there is expression of TLR-1, 2, 3, 4, 5, 6, 9 and 10 and the expression of TLR-1, 2, 4, and 6 are increased with degree of disc degeneration and pain (23). Overloading of intact disc and IVD cells can upregulate TLR-2 and 4 expression, and previous data from our lab demonstrates that activating TLR receptors with the synthetic agonists (PAM2csk4, TLR-2/6 agonist) induced IVD degeneration (23-25). Furthermore, studies using multiple cell lines proposed that TLR activation is associated with the induction of senescent cells and SASP factor release (26-28).

The present study investigates a possible link between the increase of TLRs and senescent cells in degenerate IVDs from patients undergoing surgery for low back pain. We show that a TLR-2/6 agonist increased the number of senescent cells from non-degenerate IVDs and in cells from degenerate IVDs. As 
well, we describe that TLR-2 has the highest expression and co-localization with senescent cells from degenerate IVDs from patients undergoing surgery for low back pain. Furthermore, treatment with oVanillin reduced the number of cells co-localized for TLR-2 and senescence markers. From this study, we propose that TLR-2 has a role in the increase of senescent cells found in degenerating IVDs and that oVanillin's senolytic and anti-inflammatory activity could be a disease modifying pharmaceutical for low back pain.

\section{Methods}

\section{Tissue collection and cell isolation}

All procedures performed were approved by the ethical review board at McGill University (IRB\#s A04-M5308B and A10-M113-13B). Non-degenerate IVDs from humans with no history of back pain were obtained through a collaboration with Transplant Quebec. Degenerate IVDs were obtained from patients with chronic low back pain that received discectomies to alleviate pain. Donor information is presented in Supplementary Table 1. IVD cells were isolated, as previously described (29). Briefly, samples were washed in phosphate-buffered saline solution (PBS, Sigma-Aldrich, Oakville, ON, Canada) and Hank'sbuffered saline solution (HBSS, Sigma-Aldrich, Oakville, ON, Canada) supplemented with Primocin ${ }^{\mathrm{TM}}$ (InvivoGen, San Diego, CA, USA) and Fungiozone (Sigma-Aldrich, Oakville, ON, Canada). Then, the matrix was minced and digested in $0.15 \%$ collagenase type II (Gibco) for 16 hours at $37^{\circ} \mathrm{C}$. Cells were passed through both a 100- $\mu \mathrm{m}$ filter and 70- $\mu \mathrm{m}$ filter, before being re-suspended in Dulbecco's Modified Eagle Media (DMEM, Sigma-Aldrich, Oakville, ON, Canada) supplemented with $10 \%$ fetal bovine serum (FBS, Gibco), Primocin ${ }^{\mathrm{TM}}$, Glutamax (Oakville, ON, Canada), and maintained in a $5 \% \mathrm{CO}_{2}$ incubator at $37^{\circ} \mathrm{C}$.

\section{In Vitro Cell Culture and Treatment}

Monolayer culture: Experiments were performed with NP cells from non-degenerate IVDs and degenerate IVDs (NP and AF cells) within passage 1 to 2. 20,000 cells were seeded in 8-well chamber slides (Nunc ${ }^{\text {TM }}$ Lab-Tek $^{\text {TM }}$ II Chamber Slide ${ }^{\text {TM }}$ System) for immunocytochemistry experiments following treatment. 300,000 cells were seeded in 6-well plates (Sarstedt, TC plate 6-well, Cell+, F) for ELISA and RNA extraction following treatment. All cells were left to adhere for 12 to 24 hours and then serum-starved in DMEM with 1X insulin-transferrin selenium (ITS, Thermo Fisher, Waltham, MA, USA) for 6 hours prior to treatment. To examine the effects of different treatments, healthy cells were treated with either $100 \mathrm{ng} / \mathrm{ml} \mathrm{Pam2CSK} 4$ (TLR-2/6 agonist, Invivogen), $100 \mathrm{ng} / \mathrm{mL}$ Pam3CSK4 (TLR-1/2 agonist, Invivogen) or $5 \mu \mathrm{g} / \mathrm{mL}$ lipopolysaccharide (LPS) (TLR-4 agonist, Invivogen) for 6, 12, 24 and 48 hours. Cells were either left untreated (negative control) or treated with $100 \mathrm{ng} / \mathrm{mL}$ of Pam2CSK 4 for 48 hours of which treatment with $100 \mu \mathrm{M}$ o-Vanillin (Sigma-Aldrich, Oakville, ON, Canada) was initiated in the last 6 hours of incubation $(18,23,30)$.

Pellet culture: 300,000 cells/tube were collected by centrifugation at $1500 \mathrm{rpm}$ for 5 minutes. Pellets were incubated in $1 \mathrm{~mL}$ DMEM, 2.25g/L glucose (Sigma-Aldrich, Oakville, ON, Canada), $5 \%$ FBS, $5 \mu \mathrm{M}$ ascorbic 
acid, $1 \%$ GlutaMAX, 0.5\% Gentamicin (Thermo Fisher, Waltham, MA, USA) at $37^{\circ} \mathrm{C}$ and $5 \% \mathrm{CO}_{2}$. Pellets were left in DMEM for four days to form and stabilize (in pretreatment media) and then treated with 100 $\mu \mathrm{M}$ o-Vanillin (Sigma-Aldrich, Oakville, ON, Canada) for four days, meanwhile pellets in the control group stayed in DMEM with vehicle 0.01\% DMSO (Sigma-Aldrich, Oakville, ON, Canada). Following the treatment period, pellets from both groups were cultured for 21 days and their culture media was collected every 4 days and pooled as post-treatment media.

\section{Immunofluorescence}

Monolayer cultures (20,000 cells/well in 8-well chambered slide) were washed with PBS, fixed with $4 \%$ paraformaldehyde (Thermo Fisher, Waltham, MA, USA), and blocked in PBS with 1\% BSA (Sigma-Aldrich, Oakville, ON, Canada), 1\% goat serum, and 0.1\% Triton X-100 (Sigma-Aldrich, Oakville, ON, Canada) for 1 hour. Pam2CSK4 treated cells were stained with primary antibodies specific to NGF (Santa Cruz, Dallas, Tx, USA), p16 Ink4a (Cintec-Roche, Laval, Qc, CAN), IL1b, TNF-a, IL8 and TLR-2 (Abcam, Cambridge, Ma, USA) overnight at $4^{\circ} \mathrm{C}$. Healthy cells were treated with $p 16^{I N K 4 a}$ and TLR-2 only. After washing, cells were incubated with the appropriate Alexa Fluor ${ }^{\circledR} 488$ or 594-conjugated secondary antibody (Thermo Fisher, Waltham, MA, USA) for 2 hours at room temperature, and then counterstained with DAPI for nuclear staining. Photomicrographs were acquired with a fluorescent Olympus BX51 microscope equipped with an Olympus DP71 digital camera (Olympus, Tokyo, Japan). Ten images of each condition per donor were analyzed and positive cell percentage was quantified by Fiji ImageJ (version: 2.1.0/1.53c). Briefly, the number of cells stained positive for one of the target proteins (NGF, IL-1b, TNF-a, and IL-8) were counted and compared to the total number of cells positive for DAPI staining. For the double staining (TLR-2 and $p 16^{I N K 4 a}$ ) the percentage of positive cells represents the ratio of the number of cells positively stained for either one of the 2 markers (TLR-2 \& $p 16^{I N K 4 a}$ ) divided by the total number of cells positively stained for DAPI.

\section{Immunohistochemistry}

Safranin-O staining: Pellet culture samples were heated on an iron heater at $50^{\circ} \mathrm{C}$ for 30 minutes and rehydrated with PBS. Samples were stained with 0.1\% Safranin-O (Sigma-Aldrich, Oakville, ON, Canada) for 5 minutes at room temperature and rinsed with water, 75\% ethanol (15s), and 95\% ethanol (15s). Coverslips were mounted with Permount ${ }^{\mathrm{TM}}$ Mounting Medium (Fisher Scientific). Samples were imaged with Olympus DP70 digital camera (Olympus) pre-fixed to a Leica microscope (Leica DMRB) under visible light.

p16 ${ }^{\text {INK4a }}$ staining: $p 16^{\text {INK4a }}$ staining was performed for both monolayer cultures and pellet samples. Only the pellet samples were heated on an iron heater at $50^{\circ} \mathrm{C}$ for 30 minutes and rehydrated by PBS-T (0.1\% Triton X-100) for 10 minutes. Both healthy monolayer cultures and pellet samples were blocked with hydrogen peroxide for 10 minutes, washed three times, and saturated with $1 \%$ BSA, $1 \%$ goat serum, and $0.1 \%$ Triton X-100 for 10 minutes. All samples were incubated at $4^{\circ} \mathrm{C}$ overnight for $p 16^{I N K 4 a}$ antibody (CINTec Kit, Roche) and PBS-T for negative control. The HRP/DAB Detection IHC Kit (Abcam, ab64264) 
was used for detection. Counting staining was applied with Meyer's hematoxylin (Sigma-Aldrich, Oakville, ON, Canada) for 2 minutes. Samples were rinsed with water (30s), 75\% ethanol (15s), and 95\% ethanol (15s) afterwards and coverslips were mounted with Permount ${ }^{\mathrm{TM}}$ Mounting Medium (Fisher Scientific). Images were captured as described (18) for Safranin-O staining, and analyzed with Fiji Image J (version 2.1.0/1.53c).

\section{Real-time Quantitative Polymerase Chain Reaction (RT-qPCR)}

RNA was extracted using the TRIzol chloroform extraction method previously described (31). $500 \mathrm{ng}$ of RNA was then reverse transcribed using a qScript cDNA Synthesis Kit (Quanta Biosciences, Beverly, MA, USA) with an Applied Biosystems Verti Thermocycler (Thermo Fisher, Waltham, MA, USA). RT-qPCR was performed using an Applied Biosystems StepOnePlus machine (Thermo Fisher, Waltham, MA, USA) with PerfecCTa SYBR Green Fast Mix (Quanta Biosciences, Beverly, MA, USA). Primer sequences for TLRs, senescent markers, pain and inflammatory markers (IL-6, IL-8, p16, p21, TNF-a, CXCL-10, CXCL-1, GM-CSF, TGF-b, CCL-2, CCL-5, CCL-7, CCL-8, NGF, BDNF, IL-8, TLR-1,2,4,6) and the housekeeping gene (GAPDH) can be found in Supplementary Table 2. All reactions were conducted in technical triplicate, and fold-changes in gene expression were calculated by using the $2^{-\Delta \Delta C t}$ method, after normalizing to actin and non-treated samples (32).

\section{Protein analysis}

To determine the concentration of NGF, IVD cells were cultured in monolayer (250,000 cells/sample) and then lysed using $300 \mu \mathrm{L}$ of Cell Lysis buffer (RayBiotech, Norcoss, GA, USA). Cell lysates were incubated

for 48 hours at room temperature and protein concentrations were determined using ELISA kits, according to the manufacturer's instructions (RayBiotech, Norcoss, GA, USA). Cell culture media from degenerate IVD cells cultured in monolayer and in pellets was used to assess the concentrations of IL-6, IL-8, IL$1 \mathrm{~b}$ and TNF-a. $150 \mu \mathrm{L}$ of monolayer culture media and pellet pre-treated and pooled post-treated media was used. ELISAs were performed as per the manufacturer's instructions (RayBiotech, Norcoss, GA, USA). Colorimetric absorbance was measured with a Tecan Infinite M200 PRO (Tecan, Männedorf, Switzerland) spectrophotometer and analyzed with i-control 1.9 Magellan software (Tecan, Männedorf, Switzerland). Protein levels of the treated conditions and controls were then compared.

\section{Dimethylmethylene Blue Assay}

Dimethylmethylene Blue (DMMB) assays were conducted as previously described (18) to quantify sulfated glycosaminoglycans (sGAG) in the conditioned media of IVD pellets with or without o-Vanillin treatment. Chondroitin sulfate was used to generate the standard curve. Pooled post-treatment media samples from treated and untreated pellets were used. All samples were ensured to fall into the linear portion of the standard curve. Each sample was placed in triplicate into clear 96-well plates (Costar, Corning, NY, USA). DMMB dye was then added to the wells. The absorbance was measured immediately at room temperature using Tecan Infinite T200 spectrophotometer (Mannedorf, Switzerland). 


\section{Statistical analysis:}

Data was analyzed using Graph Prism 8 (Graph Pad, La Jolla, CA, USA). Analysis was performed using two-tailed Student's t test or Two-way ANOVA. Specific tests are indicated in the figure legends with the corrections. A p-value $<0.05$ was considered statistically significant. Data are presented as mean \pm SD.

\section{Results}

\section{Cell activation with a TLR-2/6 agonist, caused an increase in the number of senescent cells and SASP factor release in cells from non-degenrate human IVDs}

We have previously reported that TLR expression and the number of senescent cells are positively correlated with level of IVD degeneration $(18,23)$. Moreover, we have seen that treating cells from degenerating human IVDs with TLR agonists PAM2csk4 (TLR-2/6), PAM3csk4 (TLR- 1/2) and LPS (TLR4) increased expression of pain mediators and pro-inflammatory cytokines when compared to vehicle control (23). Here we aimed to determine the effect and the relation of TLR activation and cell senescence in human IVD cells from non-degenrate IVDs. Monolayer cultures were treated with TLR agonists activating TLR-2/6, 1/2 and 4 for $6,12,24$ and 48 hours. p16 ink4a was used to identify senescent cells and the number of senescent cells were significantly increased following TLR-2/ 6 activation with a $11 \% \pm 1.732$ increase at 24 hours $(p<0.001)$ and a $22.67 \% \pm 4.163(p<0.0001)$ increase at 48 hours (Fig.1A-B). Furthermore, using RT-qPCR the gene expression levels of TLRs, senescense markers and SASP factors were evaluated in the treated cell pellets. The expression of the TLR-1,2,4,6 in pellets treated with TLR agonists for 48 hours was investigated. A significant increase $(7.24$-fold $\pm 3.458, p<0.001)$ in expression of the TLR-2 in the cells exposed to the TLR-2/6 agonist was observed when normalized to the untreated control. Significance was not reached for TLR-1 $(p=0.9995)$, TLR-4 $(p=0.9974)$ and TLR-6 $(p=$ 0.1080 ) (Fig. 1C). Moreover, a significant increase (2.56-fold $\pm 0.288, p<0.001)$ of $p 16^{\text {ink }} 4 a$ gene expression only in cells exposed to the TLR-2/ 6 agonist when compared to control was observed. Of note, no significant difference was found in $p 21$ gene expression following exposure to TLR2/ 6 agonist ( $p=$ 0.8557) (Fig. 1D). When evaluating SASP factors after 48 hours of exposure to the TLR agonists, the most significant increase was observed following TLR2/ 6 exposure (Fig. 1E). Comparing to the control, an increase in CCL2 (12.70 -fold $\pm 2.541, p<0.05)$, CCL5 (55.11- fold $\pm 2.696, p<0.01)$, CCL7 (13.78fold $\pm 2.440, p<0.05)$, CCL8 (12.68-fold $\pm 1.534, p<0.05)$, IL-6 (1079.12-fold $\pm 43.135, p<0.01)$, IL-8 (1890.28-fold $\pm 85.617, p<0.01)$, TNF-a (5.30-fold $\pm 0.214, p<0.01)$, NGF (3.49-fold $\pm 0.250, p<0.05)$ and BDNF (3.31-fold $\pm 0.051, p<0.01)$ was seen following TLR2/ 6 activation (Fig. 1E). Altogether, these results validate that activation of TLR-2/ 6 increases both the number of senescent cells and SASP factors produced in cells from non-degenerate IVDs.

\section{0-Vanillin reduced the number of senescent cells and enhanced proteoglycan production in cell pellet cultures from degenerate IVDs}


O-Vanillin senolytic activity and effect on matrix production has never been assessed on cells from patients with back pain and degenerating IVDs. Here we evaluated o-Vanillin's senolytic activity in 3D pellet cultures of IVD cells back pain patients. The pellet cultures were treated with o-Vanillin $(100 \mathrm{mM})$ or vehicle (DMSO $0.01 \%$ ) for 4 days. At the end of the treatment period, the pellets were maintained in standard culture media for 21 days with the post treatment media collection occurring every 4 days. The senolytic activity was evaluated by immunostaining for the senescence marker p16 ink4a (Fig. 2A). The percentage of $16^{\text {ink } 4 a}$ positive cells decreased significantly from $14.66 \% \pm 2.758$ in the untreated control to $6.38 \% \pm 0.4973$ in the o-Vanillin treated pellets $(p<0.05)$ (Fig. 2B). Safranin-O staining was used to evaluate proteoglycan content. A more intense red staining was observed, indicating higher proteoglycan content in the o-Vanillin treated IVD cell pellets compared to the control sample (Fig. 2C). Furthermore, a DMMB assay was performed to assesses SGAG content in the culture media (33). Pooled media from all post-treatment time points in the o-Vanillin treated cell pellets $(1.62 \mathrm{mg} / \mathrm{ml} \pm 0.4134)$ had significantly higher sGAG content then the untreated control pellets $(0.33 \mathrm{mg} / \mathrm{ml} \pm 0.2876)(p<0.05)$ (Fig. 2D). We then evaluated o-Vanillin's ability to reduce SASP factors (IL-1b, IL-8, IL- 6 and TNF-a) that are commonly produced by senescent IVD cells (18). Using ELISA immunoassay, we compared the percent difference of the pooled post-treated media over the pre-treated media. A significant decrease was observed in all evaluated SASP factors measured in the media of o-Vanillin treated compared to the untreated controls. The percentage of difference in post compared to pre-treatment and measured in o-Vanillin and control groups were respectively for IL-1b $(13.75 \% \pm 3.473$ vs $30.63 \% \pm 3.279, \mathrm{p}<0.01)$, IL-8 $(38.38 \% \pm 12.903$ vs $61.5 \% \pm 18.821, \mathrm{p}<0.05)$, IL-6 $(13.38 \% \pm 5.867$ vs $25.75 \% \pm 1.652, \mathrm{p}<0.05)$ and TNF-a $(19.38$ $\% \pm 0.408$ vs $46 \% \pm 0.750, p<0.0001$ ) (Fig. 2E).

\section{o-Vanillin reduced gene expression of p16, TLR-2 and SASP factors following TLR-2 activation in IVD cells from patients with back pain and IVD degeneration}

IVD cells from patients with back pain and IVD degeneration were exposed the TLR-2/6 agonist for 48 hours in the presence or absence of o-Vanillin $(100 \mathrm{mM})$ during the last 6 hours of the treatment. We first assessed gene expression of senescece markers p16 and p21. Similar to the effect observed in cells from non-degenerate IVDs, there was a significant increase in $p 16^{\text {ink4a }}$ expression $(3.83$-fold $\pm 1.055, p<0.001$ ) and no significant difference in the expression of $p 21(p=0.4279)$ following TLR-2/ 6 exposure when compared to the untreated control (Fig. 3A). Interestingly, treatment with o-Vanillin significantly decreased p16 $6^{\text {ink4a }}$ expression $(1.07$-fold $\pm 0.308, p<0.001$ ) while no significant change was found for $p 21$ expression $(p=0.244)$ (Fig. $3 A$ ). When assessing TLR expression in the cells from patients with back pain and IVD degeneration, a significant increase in TLR-2 gene expression (9.17-fold $\pm 1.594, p<0.001$ ) following TLR-2/ 6 exposure, compared to the control was seen. However, there was no significant increase in TLR-1 $(p=0.2420)$, TLR-4 $(p=0.9985)$ or TLR-6 $(p=0.3491)$ (Fig. 3B). These samples, when treated with o-Vanillin showed a significant decrease $(1.67$-fold $\pm 0.565, p<0.001)$ in TLR-2 expression (Fig. 3B). Exposure of IVD cells from patients with back pain and IVD degeneration to TLR-2/6 agonist significantly increased the expression of SASP factors CCL2 (42.32-fold $\pm 11.337, p<0.001)$, CCL5 (49.03-fold $\pm 11.487, p<0.001)$, CCL7 (9.30-fold $\pm 1.430, p<0.01)$, CCL8 $(28.40$-fold $\pm 4.936, p<0.001$ ), 
GM-CSF (118.55-fold $\pm 10.067, p<0.001)$, BDNF (1.77-fold $\pm 0.126, p<0.01)$, NGF (2.75-fold $\pm 0.586, p<$ 0.01), TNF-a (7.36-fold \pm 2.361 , $p<0.001$ ), CLCX1 (594.16-fold $\pm 44.718, p<0.001)$, IL-8 (594.5-

fold $\pm 98.644, p<0.001)$ and CLCX10 (745.23-fold $\pm 107.787, p<0.001)$ when compared to the untreated control (Fig. 3C). o-Vanillin significantly reduced this increase, CCL2 (5.89-fold $\pm 2.075, p<0.001)$, CCL5 (6.21-fold $\pm 2.156, p<0.001)$, CCL7 (3.51-fold $\pm 1.521,0.001)$, CCL8 (2.8-fold $\pm 2.281, p<0.01)$, GM-CSF (6.33-fold $\pm 2.39, p<0.001)$, BDNF (0.85-fold $\pm 0.368, p<0.01)$, NGF (0.62-fold $\pm 0.135, p<0.01)$, TNFa (1.09-fold $\pm 0.656, p<0.001)$, CLCX1 (24.67-fold $\pm 5.132, p<0.01)$, IL-8 (75.49-fold $\pm 18.608, p<0.01$ ) and CLCX10 (10.8-fold $\pm 3.087, p<0.001)$ (Fig. 3C).

\section{o-Vanillin reduced the protein expression of SASP factors (IL-1b, NGF, IL-8 and TNF-a) following TLR-2/6 activation of IVD cells from patients with back pain and IVD degeneration}

Protein expression of (TNF-a, IL-1b, IL-8 and NGF) was evaluated by immunohistochemistry following a 48 hrs exposure to TLR-2/ 6 agonist. (Fig. 4A-D). Quantification of the percentage of positive cells for each SASP factor was compared to untreated controls. A significant increase of TNF-a $(56.6 \% \pm 2.881$ vs $95 \% \pm 1.155, p<0.001)$, IL- $1 \mathrm{~b}(56.4 \% \pm 3.050$ vs $94.25 \% \pm 0.957, \mathrm{p}<0.001)$, IL-8 $(44.2 \% \pm 1.924$ vs $84 \% \pm 2.236, p<0.001)$ and NGF $(63.6 \% \pm 2.408$ vs $92.15 \% \pm 1.388, p<0.001)$ positive cells was observed (Fig. 4E). When evaluating the effect of o-Vanillin, a significant decrease was observed in protein expression in the treated samples for TNF-a $(74.5 \% \pm 3.109, \mathrm{p}<0.01)$, IL-1b $(75 \% \pm 0.816, \mathrm{p}<$ $0.01)$, IL-8 (48.4\% $\pm 5.550, p<0.01)$ and NGF $(70.46 \% \pm 2.416, p<0.01)$ (Fig. 4E). Additionally, to measure the concentrations of SASP factors affected by TLR-2/ 6 activation and o-Vanillin treatment we performed ELISAs immunoassay of the culture media for TNF-a, IL-1b, IL-8 and on the cell lysate for NGF. A significant increase was found in the SASP factors in the culture media following TLR-2/6 activation, TNF-a $(72.03 \mathrm{pg} / \mathrm{ml} \pm 9.044 \mathrm{vs} 284.25 \mathrm{pg} / \mathrm{ml} \pm 30.972, \mathrm{p}<0.001), \mathrm{IL}-1 \mathrm{~b}(10.97 \mathrm{pg} / \mathrm{ml} \pm 1.09 \mathrm{vs} 42.11$ $\mathrm{pg} / \mathrm{ml} \pm 3.022, \mathrm{p}<0.01), \mathrm{IL}-8(92.95 \mathrm{pg} / \mathrm{ml} \pm 8.385 \mathrm{vs} 406.25 \mathrm{pg} / \mathrm{ml} \pm 39.891, \mathrm{p}<0.001)$ and in the cell lysate for NGF $(186 \mathrm{pg} / \mathrm{ml} \pm 5.957 \mathrm{vs} 355.03 \mathrm{pg} / \mathrm{ml} \pm 27.086, \mathrm{p}<0.001)$ when compared to the control and that this induction was significantly decreased for all evaluated SASP factors following treatment with o-Vanillin (TNF-a: $104.5 \mathrm{pg} / \mathrm{ml} \pm 28.831$ ( $\mathrm{p}<0.001$ ), IL-1b: $21.15 \mathrm{pg} / \mathrm{ml} \pm 2.123(\mathrm{p}<0.05), \quad \mathrm{LL}-8: 117.8$ $\mathrm{pg} / \mathrm{ml} \pm 36.944$ ( $\mathrm{p}<0.001)$ and NGF: $262.83 \mathrm{pg} / \mathrm{ml} \pm 5.208(\mathrm{p}<0.001))$ (Fig. 4F).

\section{o-Vanillin reduced the number of cells co-expressing TLR- 2 and p $16^{\text {ink } 4 a}$ in cells exposed to TLR-2/6 agonist}

Based on our findings that exposure to TLR-2/6 agonist caused a significant increase in p16 ink4a and TLR-2 gene expression in both cell and pellet cultures from non-degenrate and degenerate IVDs, we investigated the possiblilty that senescent IVD cells have an elevated TLR-2 expression. Protein expression of TLR-2 and $\mathrm{p} 16^{\text {ink }} 4 \mathrm{a}$ was assessed by immunohistochemistry in IVD cells from patients with back pain and IVD degeneration following a 48 hrs exposure to TLR-2/6 agonist. (Fig. 5A). Quantification of TLR-2 and p $16^{\text {ink4a }}$ was done by measuring the percent of cells positive from the total cell population for the two markers. Following TLR-2/ 6 activation it was found that there was a significant increase in the expression of TLR-2 $(53.17 \% \pm 8.684, p<0.001)$ and $p 16^{\text {ink } 4 a}(47.19 \% \pm 7.951, p<0.001)$ when 
compared to untreated controls; TLR-2 $(29.92 \% \pm 9.448)$ and p $16^{\text {ink } 4 a}(25.95 \% \pm 6.071)$ (Fig. 5B-C). Furthermore, treatment with o-Vanillin for the final 6 hrs significantly reduced this increase for TLR-2 $(36.3 \% \pm 8.057, p<0.001)$ and $p 16^{\text {ink } 4 a}(31.07 \% \pm 3.854, p<0.001)$ (Fig. 5B-C). Finally, to verify the link between TLR-2 and cell senescence in IVD cells, we assessed the percentage of cells co-expressing $\mathrm{p} 16^{\text {ink } 4 a}$ and TLR- 2 by determining the percentage of senescent cells ( $\mathrm{p} 16^{\text {ink }} 4 \mathrm{a}$ positive cell) that express TLR-2. In the untreated control, $26 \% \pm 1.611$ of the senescent cells expressed TLR- 2 while following TLR2/ 6 exposure the percentage of senescent cells expressing TLR-2 increased significantly to $61.05 \% \pm$ $6.946(p<0.001)$ (Fig. 5D). The most noteworthy finding was that o-Vanillin significantly reduced the number of senescent cells expressing TLR-2 to $27.57 \% \pm 2.509(p<0.001)$ when exposed to TLR-2/6 agonist. (Fig. 5D). These findings indicate a link between TLR-2 expression, cell senescence and SASP factor production that contribute to IVD degeneration and pain. This deleterious role of TLR-2 is blocked by the dual senolytic and anti-inflammatory effects of o-Vanillin.

\section{Discussion}

Several studies including our own have demonstrated that senescent cells accumulate in degenerating IVDs, and suggested that an elevated SASP factor release and increased expression of TLRs contribute to IVD degeneration $(18,23)$. Here we have shown a potential link between the accumulation of senescent cells and TLR activation. As well, we show that o-Vanillin, a TLR antagonist and senolytic compound, has regenerative and anti-inflammatory effects on cells from degenerating IVDs (34).

In chondrocytes and IVD cells, TLRs are, in addition to molecules derived from pathogens, activated by exposure to intracellular proteins such as HSP60, HSP70, S100A8/9, HMGB1 released in response to stress and extracellular matrix fragments such as fibronectin, aggrecan, biglycan and other by-products of tissue degeneration (35). As well, it has been reported that synthetic TLR-2 and 4 agonists can induce IVD degeneration, increase inflammatory environment and increase in expression of TLRs $(23,30)$. The present study, demonstrates that TLR-2 activation, in addition to inducing an inflamatory environment, caused IVD cells from non-degenerate IVDs to become senescent. We used cells of IVDs from organ donors with no signs of degeneration or history of back pain. These IVDs have a low number of senescent cells and low levels of SASP factor release compared symptomatic degenerating IVDs (18). Our results demonstrate that the synthetic TLR2 agonist (Pam2CSK4), caused the greatest increase in senescent cell number, TLR-2 expression and SASP factor release in cells from non-degenerate IVDs after $48 \mathrm{~h}$ exposure. Our previous study using TLR-1, 2, and 4 agonists found the cytokines (IL-1b, 6, 8), chemokines, proteases (MMP3, MMP13) and TLR-2 expression were greatest following exposure to the same TLR-2/ 6 agonist in NP cells of non-degenerate IVDs (23). Other studies have shown that continuous stimulation of TLR-4 promotes cellular senescence in mesenchymal stem cells (36). Moreover, TLR-2 and 10 have been found to be key mediators of senescence in IMR90 cells, a human diploid fibroblast cell line (26).

We then verified that these findings were also seen in cells isolated from degenerating IVDs of patients undergoing surgery to reduce low back pain $(18,29)$. TLR-2 activation of cells from symptomatic IVDs 
induced expression of SASP factors (CCL-2,5,7,8,IL-6,8,GM-CSF,TNF-a,NGF,BNDF,CLCX-1,10), a senescence marker ( $\mathrm{p} 16^{\text {ink4a }}$ ) and of the TLR-2 receptor itself. Moreover, we confirmed that protein expression of SASP factors (NGF, IL-1b, TNF-a and IL-8) was higher in the TLR-2 activated cells. These proteins were chosen since they have been associated to be IVD degeneration and TLR-2 induction and have been reported to be highly expressed in degenerate human and mice IVDs $(30,37,38)$. Taken together our results validate that IVD cells from patients with back pain and IVD degeneration at both gene and protein level respond to TLR-2 activation.

The use of synthetic antagonists aimed towards TLR-2 and TLR-4 has been evaluated in a variety of inflammatory diseases (39). Antagonists such as TAK-242, a TLR-4 antagonist, has been shown to diminish LPS-induced TLR-4 signaling and inflammation in peritoneal macrophages (39). Furthermore, our own previous study demonstrated that TAK-242 reduced pain but did not provide tissue regeneration in a mouse model of back pain (18). Similar to our study, anti-inflammatory properties of o-Vanillin was reported previously in NP cells from patients undergoing surgery for disc herniation or spinal stenosis following induction by high mobility group box-1(40). Furthermore, the capability of o-Vanillin to reduce SASP factors has been previously depicted in IVD cell pellet cultures $(18,41)$. o-Vanillin has also been shown to reduce cytokines, chemokines and proteases in vitro by in human HEK-TLR2 and THP-1 cells and to reduce a tumor-promoting phenotype of microglia in vivo $(34,42)$. It has also previously been shown that o-Vanillin incorporated to Poly (Lactic-Co-Glycolic Acid) scaffolds elicited more proteoglycan production and decreased inflammatory response of annulus fibrous cells compared to cells in unsupplemented scaffolds (43). As well, o-Vanillin has been shown to significantly decrease the production of pro-inflammatory cytokines and significantly attenuated UVB irradiation-induced cytotoxicity in human keratinocyte stem cells (44).

Senolytic drugs target selective signaling pathways involved in cell survival and apoptosis (25). These drugs could potentially be used therapeutically to treat disc degeneration, recover loss of disc height in already degenerate discs, or prophylactically to prevent future degeneration either in individuals at risk or following fusion for adjacent disc disease $(45,46)$. Our previous study demonstrated that o-Vanillin, reduced senescenct cells and enhanced matrix production in cell pellet cultures generated from organ donor IVDs without known history of backpain (18). Here we show that o-Vanillin was able to reduce inflammation, remove senescent cells and enhance proteoglycan production in cell pellets from surgically removed symptomatic IVDs of patients with low back pain.

We further demonstrated that by targeting TLRs and senescent cells with o-Vanillin we can decrease inflammatory processes found in IVD cells from patients with back pain and IVD degeneration. Interestingly, our study demonstrates that both gene and protein expression of SASP factors (CCL2,5,7,8, GM-CSF, BDNF, NGF, TNF-a, CLCX1, CLCX8 and CLCX10, IL-1b, IL-8) were significantly reduced following TLR activation and o-Vanillin treatment.

The higher expression of TLR-2 in IVD cells from patients with back pain and IVD degeneration leads us to evaluate its expression level in senescent cells and investigate its role in disc cell senescence 
and associated SASP factors release. We found TLR-2 activation increased the expression of TLR-2 in the senescent cells. Also, treatment with o-Vanillin significantly reduced the number of senescent cells expressing TLR-2. One limitation of our study is that the degenerate cell population is a mix of NP and AF cells from patients suffering from chronic lower back pain. This is because the difficulty to accurately distinguish and separate NP and AF tissue from surgically removed IVD tissue.This limitation does not allow us to know whether the TLR-2/p-16 co-localization is in both cell types or in AF or NP cells specifically. To our knowledge this is the first study to show a potential link between TLR-2 and cellular senescence in IVD cells. Further studies using genetically modified TLR-2 knock-out human IVD cell lines are needed to better decipher which mechanisitic pathways are shared between o-Vanillin's senolytic activity and TLR-2's antagonistic effect.

\section{Conclusions}

We showed that TLR-2/ 6 activation increased TLR-2 expression and senescent cells in IVD cells from both organ donors without degeneration and backpain and patients with disc degeneration and backpain. Further, o-Vanillin reduced the number of senescent IVD cells and the release of SASP factors. This data suggests a possible regulatory effect between TLR-2 and IVD cell senescence IVD. This phenomenon could be explained either by the induction of non-scenescent neighbouring cells by senescent cells in a paracrine manner or alternatively that senescent cells retain SASP factor production through TLR-2 activation in an autocrine manner. The detrimental effect of senescent cells can be inhibited by blocking TLR-2 activity with o-Vanillin. These findings prompt the need to further understand the role of TLR-2 in IVD cell senescence and the mechanism by which o-Vanillin interferes in this pathway.

\section{Abbreviations}

IVD = intervertebral disc

TLR $=$ Toll-like receptors

SASP $=$ senescence-associated secretory phenotype

Dimethyl-Methylene Blue Assay = DMMB

ICC = immunocytochemistry

ELISA = enzyme-linked immunosorbent assay

$\mathrm{NP}=$ nucleus pulposus

$\mathrm{AF}=$ annulus fibrosus

sGAG = sulfated glycosaminoglycans 


\section{Declarations}

Ethics and Consent to participate:

IVD tissue used in this study were provided by Transplant Quebec or McGill Scoliosis and Spine Group.

Tissues were collected during discectomies to allievate pain or during organ harvesting. Participants provided written informed consent to participate in the study and to allow their biological samples to be tested. All procedures performed were approved by the ethical review board at RI-MUHC (IRB \# Tissue Biobank 2019-4896, Extracellular Matrix 2020-564 and A08-M22-17B).

Consent for publication:

Not Applicable

Availbility of data and materials:

The datasets used and analyzed during the current study are available from the corresponding author on reasonable request.

Competing interests:

The authors declare that they have no competing interests

Funding:

This work was supported by the Canadian Institutes of Health Research (CIHR) MOP-119564, a major infrastructure grant and by the Réseau de Recherche en Santé Buccodentaire et Osseuse (RSBO). MM received a studentship from MITACS

\section{Authors' contributions}

All authors read and approved the final manuscript. MM received a studentship from MITACS. MM and $\mathrm{HC}$ designed the study, conducted experiments, analysed data and wrote the manuscript. LL and KS conducted experiments. OR, JO, MW and PJ helped to design the study and extensively reviewed and revised manuscript. OR, JO, MW and PJ provided organ donor and surgical IVD samples. LH designed the study, wrote the manuscript and gave final approval of manuscript.

Acknowledgements

Not Applicable

\section{References}

1. Ahmed S, Anuntiyo J, Malemud CJ, Haqqi TM. Biological basis for the use of botanicals in osteoarthritis and rheumatoid arthritis: a review. Evid Based Complement Alternat Med. 
2005;2(3):301-8.

2. Elmali N, Baysal O, Harma A, Esenkaya I, Mizrak B. Effects of resveratrol in inflammatory arthritis. Inflammation. 2007;30(1-2):1-6.

3. Feng $H$, Danfelter $M$, Strömqvist $B$, Heinegård D. Extracellular matrix in disc degeneration. J Bone Joint Surg Am. 2006;88 Suppl 2:25-9.

4. Geurts JW, Willems PC, Kallewaard JW, van Kleef M, Dirksen C. The Impact of Chronic Discogenic Low Back Pain: Costs and Patients' Burden. Pain Res Manag. 2018;2018:4696180.

5. Phillips CJ. The Cost and Burden of Chronic Pain. Rev Pain. 2009;3(1):2-5.

6. Gorth DJ, Shapiro IM, Risbud MV. Discovery of the drivers of inflammation induced chronic low back pain: from bacteria to diabetes. Discov Med. 2015;20(110):177-84.

7. Muñoz-Espín D, Serrano M. Cellular senescence: from physiology to pathology. Nat Rev Mol Cell Biol. 2014;15(7):482-96.

8. Toussaint O, Dumont P, Dierick JF, Pascal T, Frippiat C, Chainiaux F, et al. Stress-induced premature senescence as alternative toxicological method for testing the long-term effects of molecules under development in the industry. Biogerontology. 2000;1(2):179-83.

9. Toussaint O, Medrano EE, von Zglinicki T. Cellular and molecular mechanisms of stress-induced premature senescence (SIPS) of human diploid fibroblasts and melanocytes. Exp Gerontol. 2000;35(8):927-45.

10. Schaefer L. Complexity of danger: the diverse nature of damage-associated molecular patterns. $J$ Biol Chem. 2014;289(51):35237-45.

11. Aan GJ, Hairi HA, Makpol S, Rahman MA, Karsani SA. Differences in protein changes between stressinduced premature senescence and replicative senescence states. Electrophoresis. 2013;34(15):2209-17.

12. Debacq-Chainiaux F, Borlon C, Pascal T, Royer V, Eliaers F, Ninane N, et al. Repeated exposure of human skin fibroblasts to UVB at subcytotoxic level triggers premature senescence through the TGFbeta1 signaling pathway. J Cell Sci. 2005;118(Pt 4):743-58.

13. Parrinello S, Coppe JP, Krtolica A, Campisi J. Stromal-epithelial interactions in aging and cancer: senescent fibroblasts alter epithelial cell differentiation. J Cell Sci. 2005;118(Pt 3):485-96.

14. Tominaga $\mathrm{K}$. The emerging role of senescent cells in tissue homeostasis and pathophysiology. Pathobiol Aging Age Relat Dis. 2015;5:27743.

15. Acosta JC, Banito A, Wuestefeld T, Georgilis A, Janich P, Morton JP, et al. A complex secretory program orchestrated by the inflammasome controls paracrine senescence. Nat Cell Biol. 2013;15(8):978-90.

16. A Study of Single and Repeat Dose Administration of UBX0101 in Patients With Osteoarthritis of the Knee. https://ClinicalTrials.gov/show/NCT04229225.

17. Short S, Fielder E, Miwa S, von Zglinicki T. Senolytics and senostatics as adjuvant tumour therapy. EBioMedicine. 2019;41:683-92. 
18. Cherif H, Bisson DG, Jarzem P, Weber M, Ouellet JA, Haglund L. Curcumin and o-Vanillin Exhibit Evidence of Senolytic Activity in Human IVD Cells In Vitro. J Clin Med. 2019;8(4).

19. Cherif H, Bisson DG, Mannarino M, Rabau O, Ouellet JA, Haglund L. Senotherapeutic drugs for human intervertebral disc degeneration and low back pain. Elife. 2020;9.

20. Jeon OH, Kim C, Laberge RM, Demaria M, Rathod S, Vasserot AP, et al. Local clearance of senescent cells attenuates the development of post-traumatic osteoarthritis and creates a pro-regenerative environment. Nat Med. 2017;23(6):775-81.

21. Szallasi A, Cortright DN, Blum CA, Eid SR. The vanilloid receptor TRPV1: 10 years from channel cloning to antagonist proof-of-concept. Nat Rev Drug Discov. 2007;6(5):357-72.

22. Heger M, van Golen RF, Broekgaarden M, Michel MC. The molecular basis for the pharmacokinetics and pharmacodynamics of curcumin and its metabolites in relation to cancer. Pharmacol Rev. 2014;66(1):222-307.

23. Krock E, Rosenzweig DH, Currie JB, Bisson DG, Ouellet JA, Haglund L. Toll-like Receptor Activation Induces Degeneration of Human Intervertebral Discs. Sci Rep. 2017;7(1):17184.

24. Alkhatib B, Rosenzweig DH, Krock E, Roughley PJ, Beckman L, Steffen T, et al. Acute mechanical injury of the human intervertebral disc: link to degeneration and pain. Eur Cell Mater. 2014;28:98-110; discussion -1 .

25. Rosenzweig DH, Gawri R, Moir J, Beckman L, Eglin D, Steffen T, et al. Dynamic loading, matrix maintenance and cell injection therapy of human intervertebral discs cultured in a bioreactor. Eur Cell Mater. 2016;31:26-39.

26. Hari P, Millar FR, Tarrats N, Birch J, Quintanilla A, Rink CJ, et al. The innate immune sensor Toll-like receptor 2 controls the senescence-associated secretory phenotype. Sci Adv. 2019;5(6):eaaw0254.

27. Lee HJ, Choi B, Kim Y, Lee SE, Jin HJ, Lee HS, et al. The Upregulation of Toll-Like Receptor 3 via Autocrine IFN- $\beta$ Signaling Drives the Senescence of Human Umbilical Cord Blood-Derived Mesenchymal Stem Cells Through JAK1. Front Immunol. 2019;10:1659.

28. Seo SW, Park SK, Oh SJ, Shin OS. TLR4-mediated activation of the ERK pathway following UVA irradiation contributes to increased cytokine and MMP expression in senescent human dermal fibroblasts. PLoS One. 2018;13(8):e0202323.

29. Gawri R, Rosenzweig DH, Krock E, Ouellet JA, Stone LS, Quinn TM, et al. High mechanical strain of primary intervertebral disc cells promotes secretion of inflammatory factors associated with disc degeneration and pain. Arthritis Res Ther. 2014;16(1):R21.

30. Krock E, Currie JB, Weber MH, Ouellet JA, Stone LS, Rosenzweig DH, et al. Nerve Growth Factor Is Regulated by Toll-Like Receptor 2 in Human Intervertebral Discs. J Biol Chem. 2016;291(7):3541-51.

31. Krock E, Rosenzweig DH, Chabot-Doré AJ, Jarzem P, Weber MH, Ouellet JA, et al. Painful, degenerating intervertebral discs up-regulate neurite sprouting and CGRP through nociceptive factors. J Cell Mol Med. 2014;18(6):1213-25.

32. Livak KJ, Schmittgen TD. Analysis of relative gene expression data using real-time quantitative PCR and the 2(-Delta Delta C(T)) Method. Methods. 2001;25(4):402-8. 
33. Mort JS, Roughley PJ. Measurement of Glycosaminoglycan Release from Cartilage Explants. In: Cope AP, editor. Arthritis Research: Methods and Protocols Volume 1. Totowa, NJ: Humana Press; 2007. p. 201-9.

34. Mistry P, Laird MH, Schwarz RS, Greene S, Dyson T, Snyder GA, et al. Inhibition of TLR2 signaling by small molecule inhibitors targeting a pocket within the TLR2 TIR domain. Proc Natl Acad Sci U S A. 2015;112(17):5455-60.

35. Minguzzi M, Cetrullo S, D'Adamo S, Silvestri Y, Flamigni F, Borzì RM. Emerging Players at the Intersection of Chondrocyte Loss of Maturational Arrest, Oxidative Stress, Senescence and LowGrade Inflammation in Osteoarthritis. Oxid Med Cell Longev. 2018;2018:3075293.

36. Feng G, Zheng K, Cao T, Zhang J, Lian M, Huang D, et al. Repeated stimulation by LPS promotes the senescence of DPSCs via TLR4/MyD88-NF-KB-p53/p21 signaling. Cytotechnology. 2018;70(3):102335 .

37. Risbud MV, Shapiro IM. Role of cytokines in intervertebral disc degeneration: pain and disc content. Nat Rev Rheumatol. 2014;10(1):44-56.

38. Krock E, Millecamps M, Anderson KM, Srivastava A, Reihsen TE, Hari P, et al. Interleukin-8 as a therapeutic target for chronic low back pain: Upregulation in human cerebrospinal fluid and preclinical validation with chronic reparixin in the SPARC-null mouse model. EBioMedicine. 2019;43:487500 .

39. Gao W, Xiong Y, Li Q, Yang H. Inhibition of Toll-Like Receptor Signaling as a Promising Therapy for Inflammatory Diseases: A Journey from Molecular to Nano Therapeutics. Front Physiol. 2017;8:508.

40. Shah BS, Burt KG, Jacobsen T, Fernandes TD, Alipui DO, Weber KT, et al. High mobility group box-1 induces pro-inflammatory signaling in human nucleus pulposus cells via toll-like receptor 4dependent pathway. J Orthop Res. 2019;37(1):220-31.

41. Santosh Kumar S, Priyadarsini KI, Sainis KB. Free radical scavenging activity of vanillin and ovanillin using 1,1-diphenyl-2-picrylhydrazyl (DPPH) radical. Redox Rep. 2002;7(1):35-40.

42. Triller P, Bachorz J, Synowitz M, Kettenmann H, Markovic D. O-Vanillin Attenuates the TLR2 Mediated Tumor-Promoting Phenotype of Microglia. Int J Mol Sci. 2020;21(8).

43. Lee $Y$, Kwon J, Khang G, Lee D. Reduction of inflammatory responses and enhancement of extracellular matrix formation by vanillin-incorporated poly(lactic-co-glycolic acid) scaffolds. Tissue Eng Part A. 2012;18(19-20):1967-78.

44. Lee J, Cho JY, Lee SY, Lee KW, Lee J, Song JY. Vanillin protects human keratinocyte stem cells against ultraviolet B irradiation. Food Chem Toxicol. 2014;63:30-7.

45. Childs BG, Durik M, Baker DJ, van Deursen JM. Cellular senescence in aging and age-related disease: from mechanisms to therapy. Nat Med. 2015;21(12):1424-35.

46. Kirkland JL, Tchkonia T. Cellular Senescence: A Translational Perspective. EBioMedicine. 2017;21:218.

47. Sandell LJ, Xing X, Franz C, Davies S, Chang LW, Patra D. Exuberant expression of chemokine genes by adult human articular chondrocytes in response to IL-1 beta. Osteoarthritis Cartilage. 
2008;16(12):1560-71.

48. Wang Y, Chang H, Zou J, Jin X, Qi Z. The effect of atorvastatin on mRNA levels of inflammatory genes expression in human peripheral blood lymphocytes by DNA microarray. Biomed Pharmacother. 2011;65(2):118-22.

49. Ullah M, Cox S, Kelly E, Moore MA, Zoellner H. Arecoline increases basic fibroblast growth factor but reduces expression of IL-1, IL-6, G-CSF and GM-CSF in human umbilical vein endothelium. J Oral Pathol Med. 2015;44(8):591-601.

50. Bayo J, Real A, Fiore EJ, Malvicini M, Sganga L, Bolontrade M, et al. IL-8, GRO and MCP-1 produced by hepatocellular carcinoma microenvironment determine the migratory capacity of human bone marrow-derived mesenchymal stromal cells without affecting tumor aggressiveness. Oncotarget. 2017;8(46):80235-48.

51. Aref-Eshghi E, Liu M, Harper PE, Doré J, Martin G, Furey A, et al. Overexpression of MMP13 in human osteoarthritic cartilage is associated with the SMAD-independent TGF- $\beta$ signalling pathway. Arthritis Res Ther. 2015;17(1):264.

52. Zhai G, Pelletier J-P, Liu M, Aitken D, Randell E, Rahman P, et al. Activation of The Phosphatidylcholine to Lysophosphatidylcholine Pathway Is Associated with Osteoarthritis Knee Cartilage Volume Loss Over Time. Scientific Reports. 2019;9(1):9648.

\section{Figures}


A

6hrs

$12 \mathrm{hrs}$
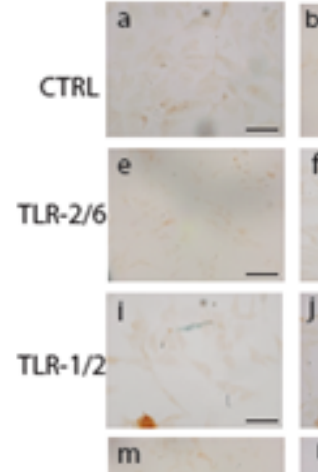

TLR-4 m
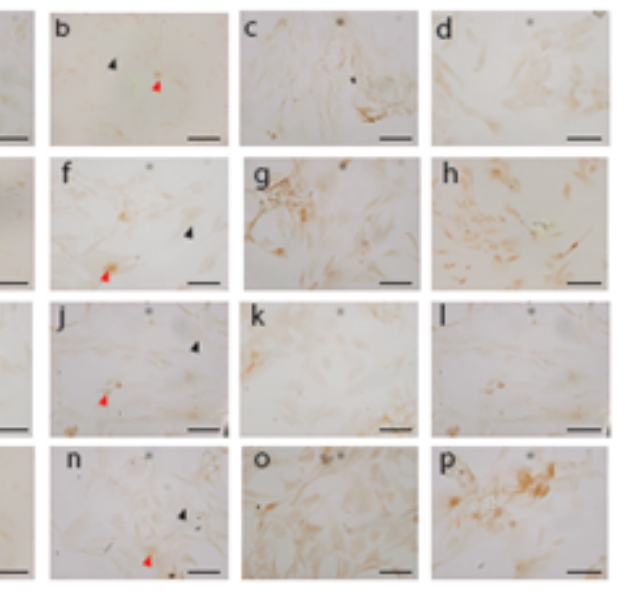

$\mathrm{C}$

E
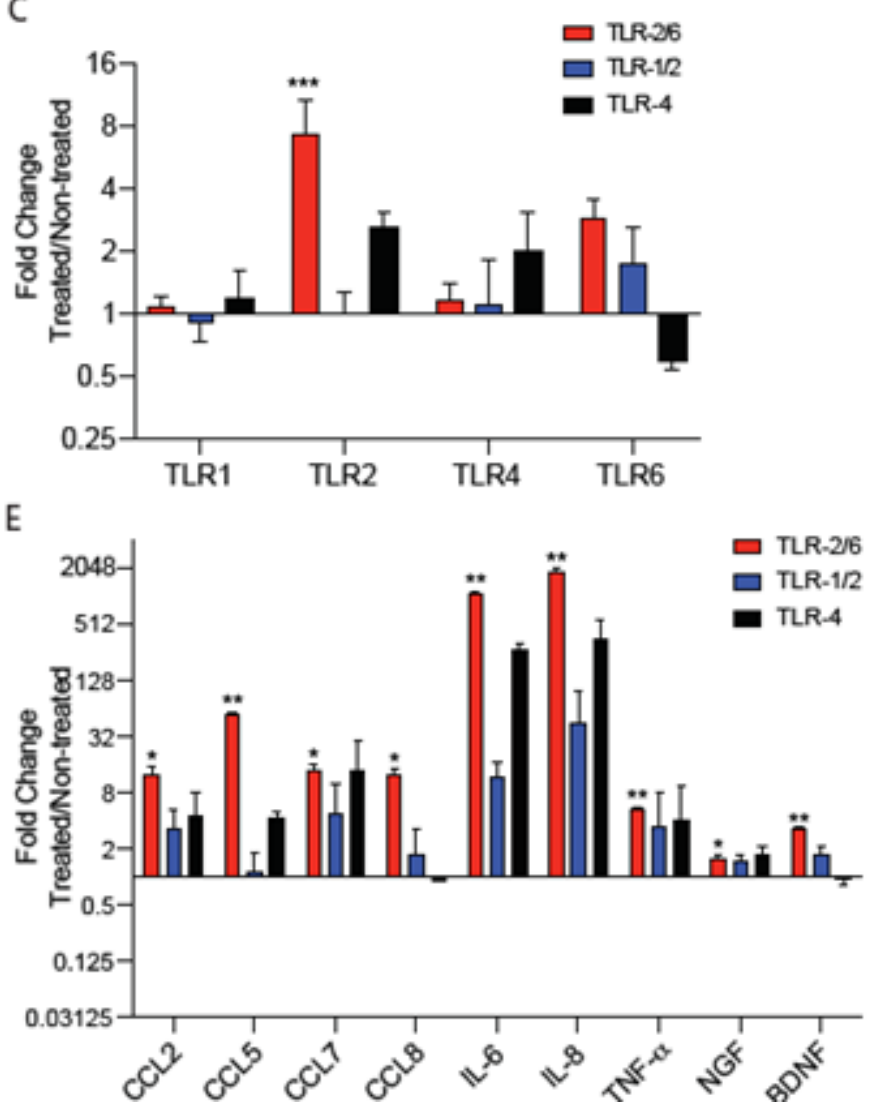

B
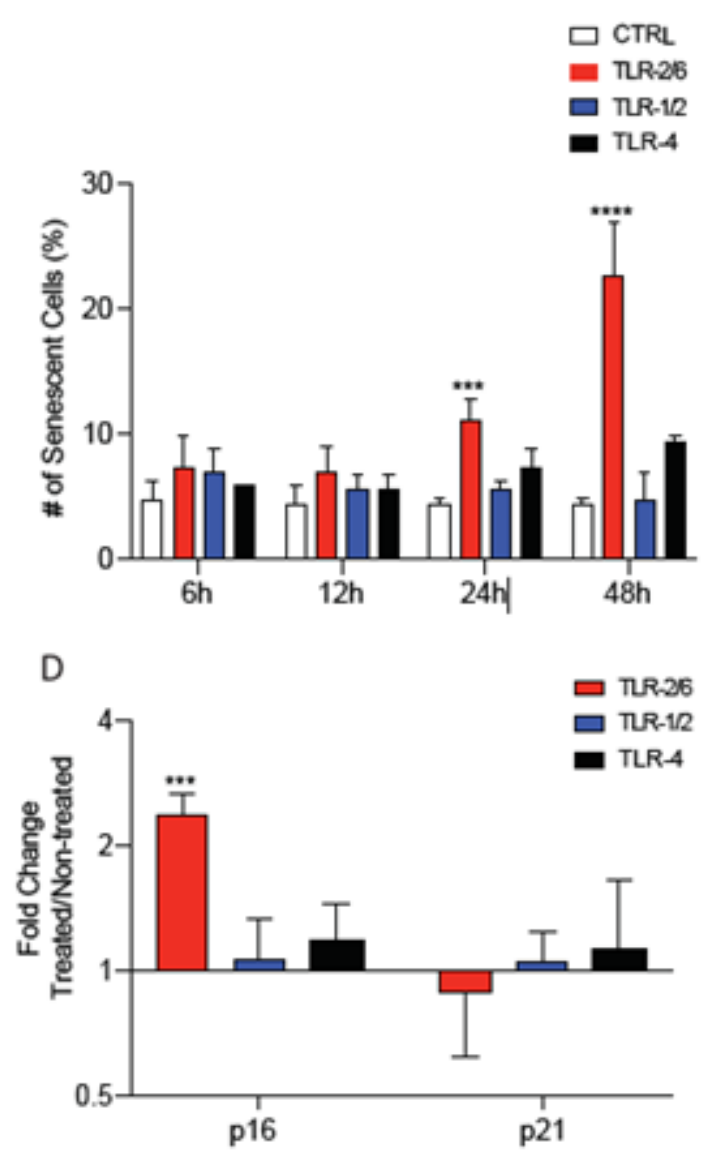

Figure 1

Cell activation with a TLR-2/6 agonist, caused an increase in the number of senescent cells and SASP factor release in cells from non-degenrate human IVDs (A) p16ink4a immunostaining images of untreated cells (a-d) from healthy donor IVDs or treated with either TLR-2/6 agonist (e-h), TLR-1/2 agonist (i-I) or TLR-4 agonist (m-p) cultured for 6, 12, 24 or 48 hours. Scale Bars $=25 \mu \mathrm{m}$. (B) Quantification of the percentage of p16ink4a positive cells in the control and treated cells for the four time points. Examples of positive cell are indicated by the red arrow and for negative cells by the black arrow. (C, D, E) qPCR was performed using cells from healthy donor IVDs cultured for 48 hours with TLR-2/ 6 agonist, TLR-1/2 agonist or TLR-4 agonist. Gene expression for (C) TLR-1, -2, -4 and -6), (D) senescence markers p16ink4a 
and p21 and (E) SASP factors (CCL2, CCL5, CCL7, CCL8, IL-6, IL-8, TNF-a, NGF and BDNF). Fold changes were normalized relative to the non-treated control (CTRL). (B-E) Two-way ANOVA with Tukey's multiple comparisons test, $n=5$, significance was was evaluated between treated groups compared to control group. Data shown as mean $\pm S D,{ }^{*} p<0.05,{ }^{* \star} p<0.01,{ }^{* \star *} p<0.001,{ }^{\star \star * \star} p<0.0001$.

A

CTRL

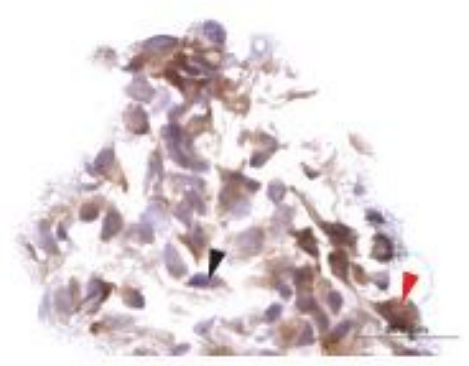

C

CTRL

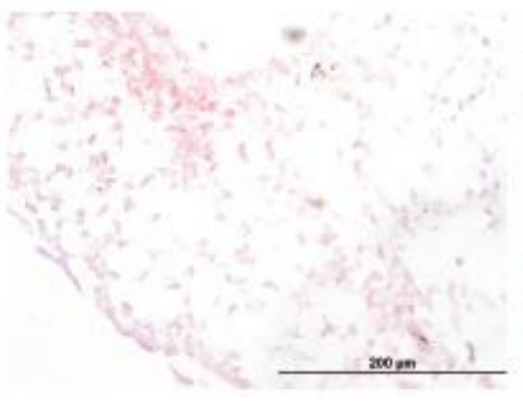

E

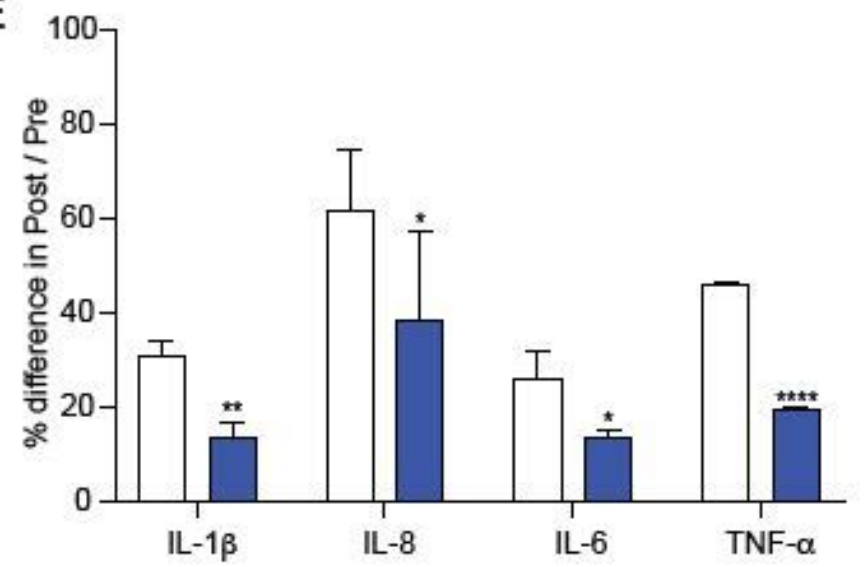

B
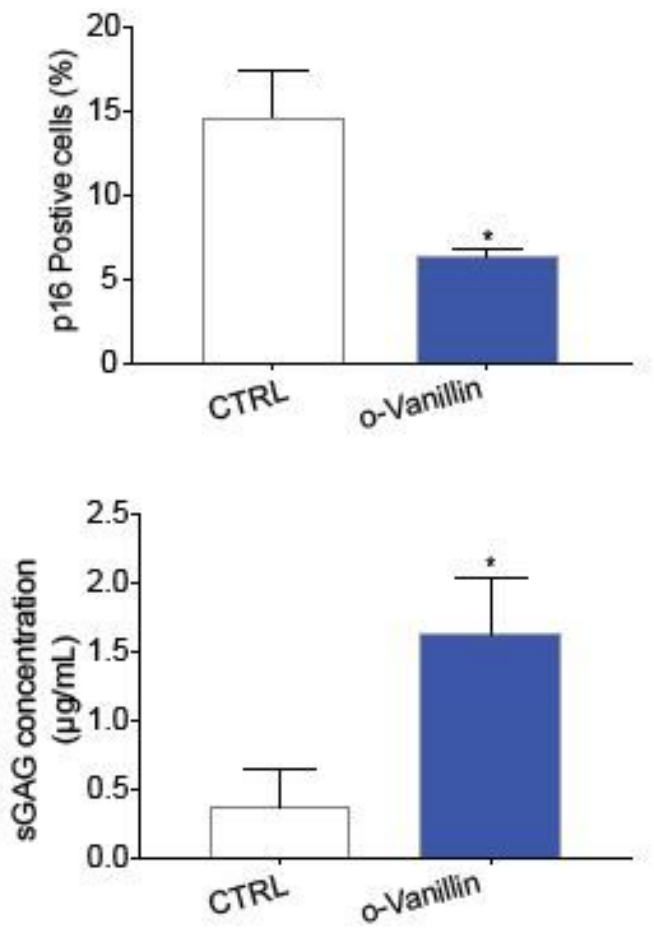

Figure 2

O-Vanillin reduced the number of senescent cells and enhanced proteoglycan production in cell pellet cultures from degenerate IVDs All experiments were performed on day 21. (A) Representative photomicrographs of p16ink4a immunohistochemistry staining in pellet cultures from degenerate IVD cells either treated with o-Vanillin or not (CTRL). Examples of positive cell are indicated by the red arrow and for negative cells by the black arrow. (B) Quantification of the percentage of p16ink4a positive cells in the pellet cultures. $n=3$ (C) Images for Safranin 0 staining for proteoglycan content in CTRL and o- 
Vanillin cell pellet cultures from degenerate IVD. (D) sGAG concentration measured using DMMB assay in the culture media of CTRL and o-Vanillin cell pellets. $n=5$ (E) Percentage of change in concentration of IL$1 \beta, I L-8, I L-6$ and TNF-a in pellet culture media from untreated and o-Vanillin treated degenerate IVD cells measured by ELISAs. Percent difference was evaluated by normalizing the post-treated media to the pretreated media. $n=5 .{ }^{*} p<0.05,{ }^{* \star} p<0.01,{ }^{* \star *} \mathrm{p}<0.0001$. (B, D, E) Mean $\pm S D$, Statistical analysis was done using paired t-test.

A

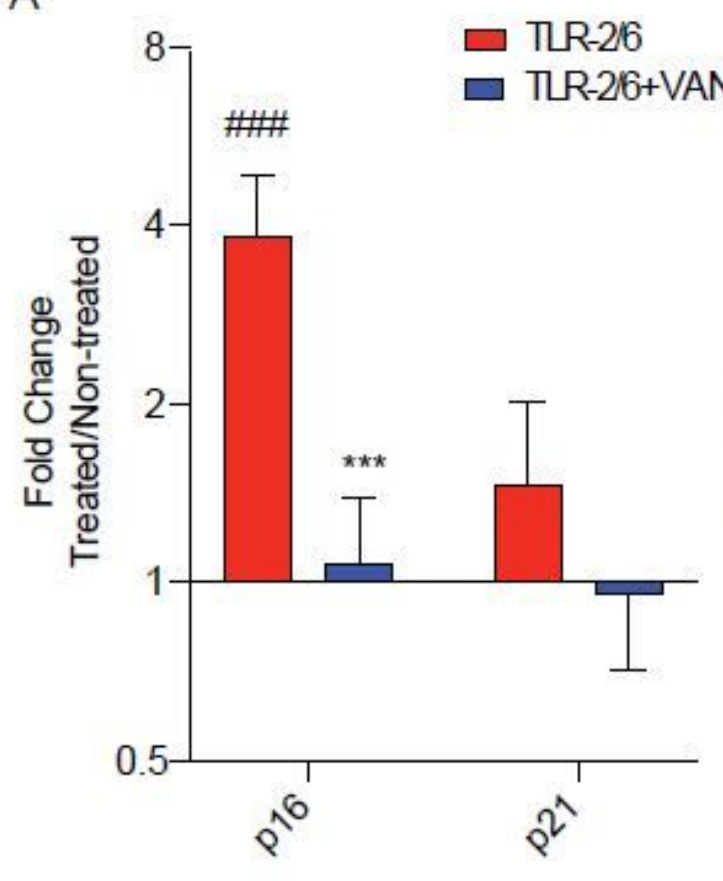

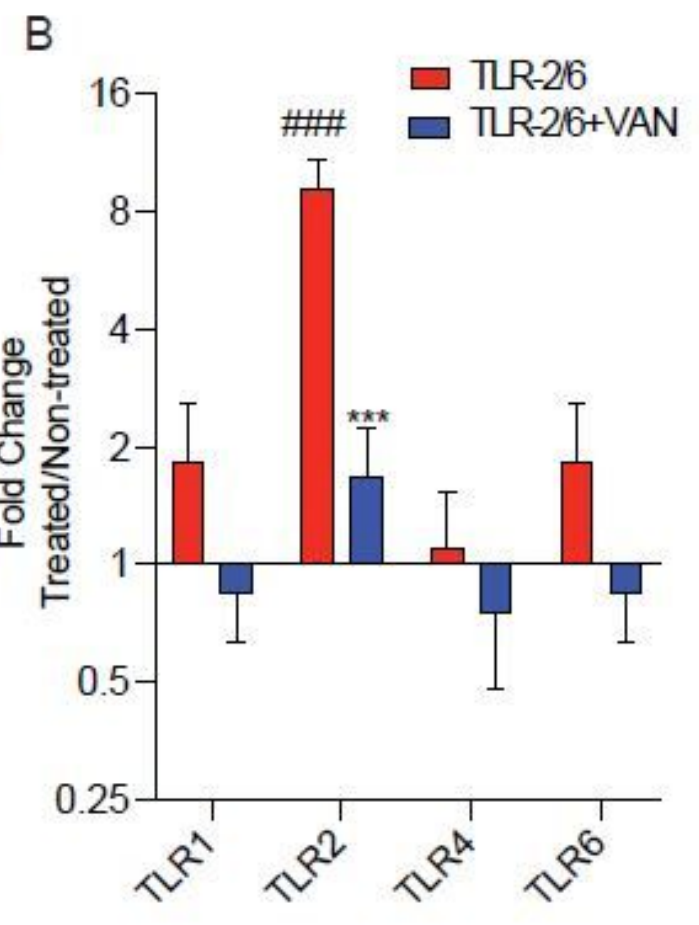

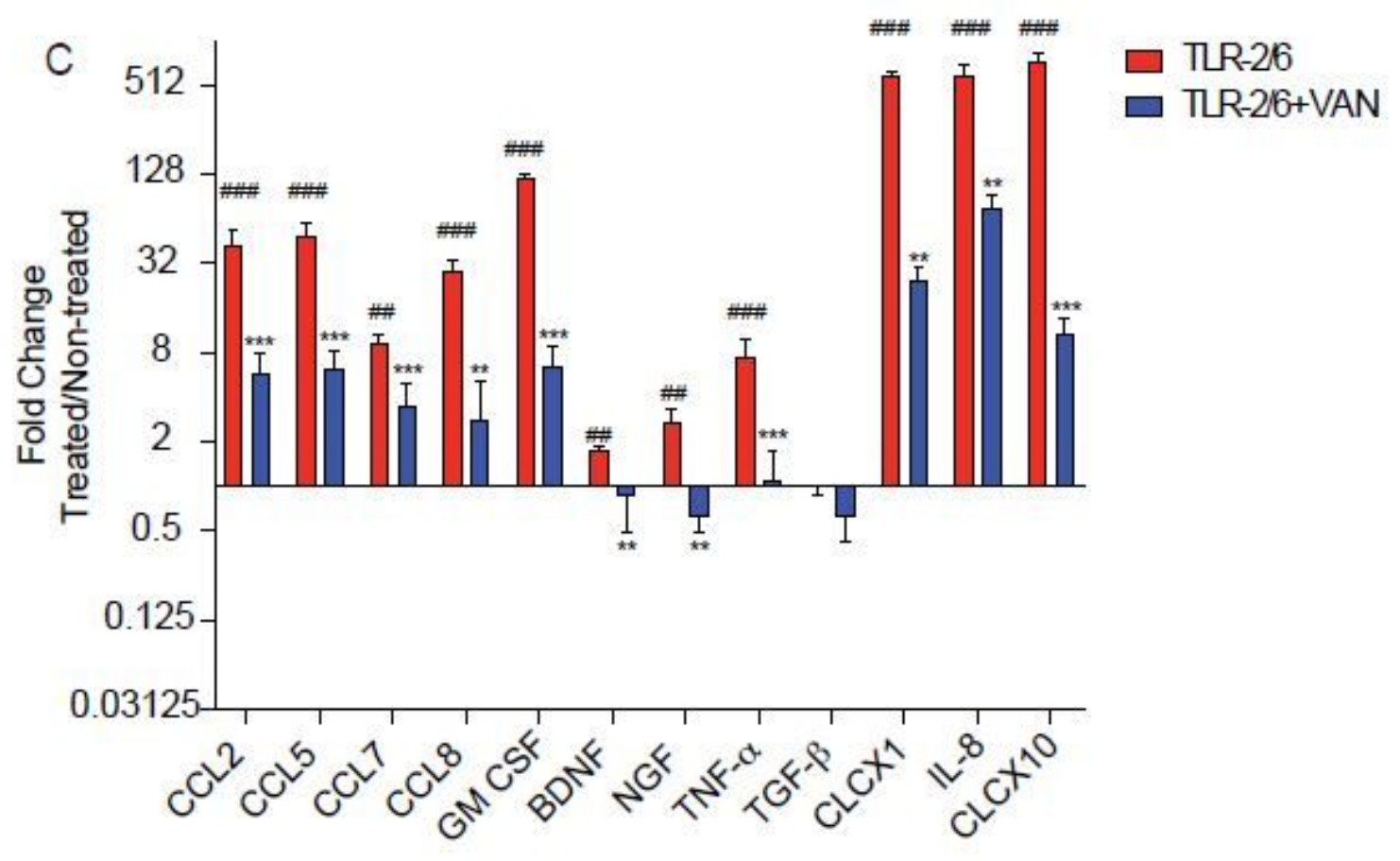

Figure 3 
o-Vanillin reduced gene expression of p16, TLR-2 and SASP factors following TLR-2 activation in IVD cells from patients with back pain and IVD degeneration (A-C) Gene expression of $(A)$ senescence markers p16ink4a and p21, (B) TLR-1, $-2,-4$ and -6 and (C) SASP factors (CCL2, CCL5, CCL7, CCL8, GM CSF, BDNF, NGF, TNF- $a$, TGF- $\beta$, CLCX1, CLCX8, CLCX10) of disc cells from degenerate IVDs cultured for 48 hours with TLR-2/ 6 agonist with o-Vanillin (TLR-2/6 + VAN) or without o-Vanillin (TLR-2/6) treatment for $6 \mathrm{~h}$ or no induction with TLR-2/6. Fold changes were normalized relative to non-induced control. $\# p<0.05$, $\# \# p<0.01, \# \# \# p<0.001$ indicate significant difference between the TLR-2/6 treated to the non-induced control and ${ }^{*} p<0.05,{ }^{*} p<0.01$, $* \star * p<0.001$ indicate significant difference between groups TLR $-2 / 6+$ VAN and TLR-2/6. (A-C) Mean \pm SD, measured by Two-way ANOVA with Sidak's multiple comparisons test. Values are expressed in average fold change for $n=5$.
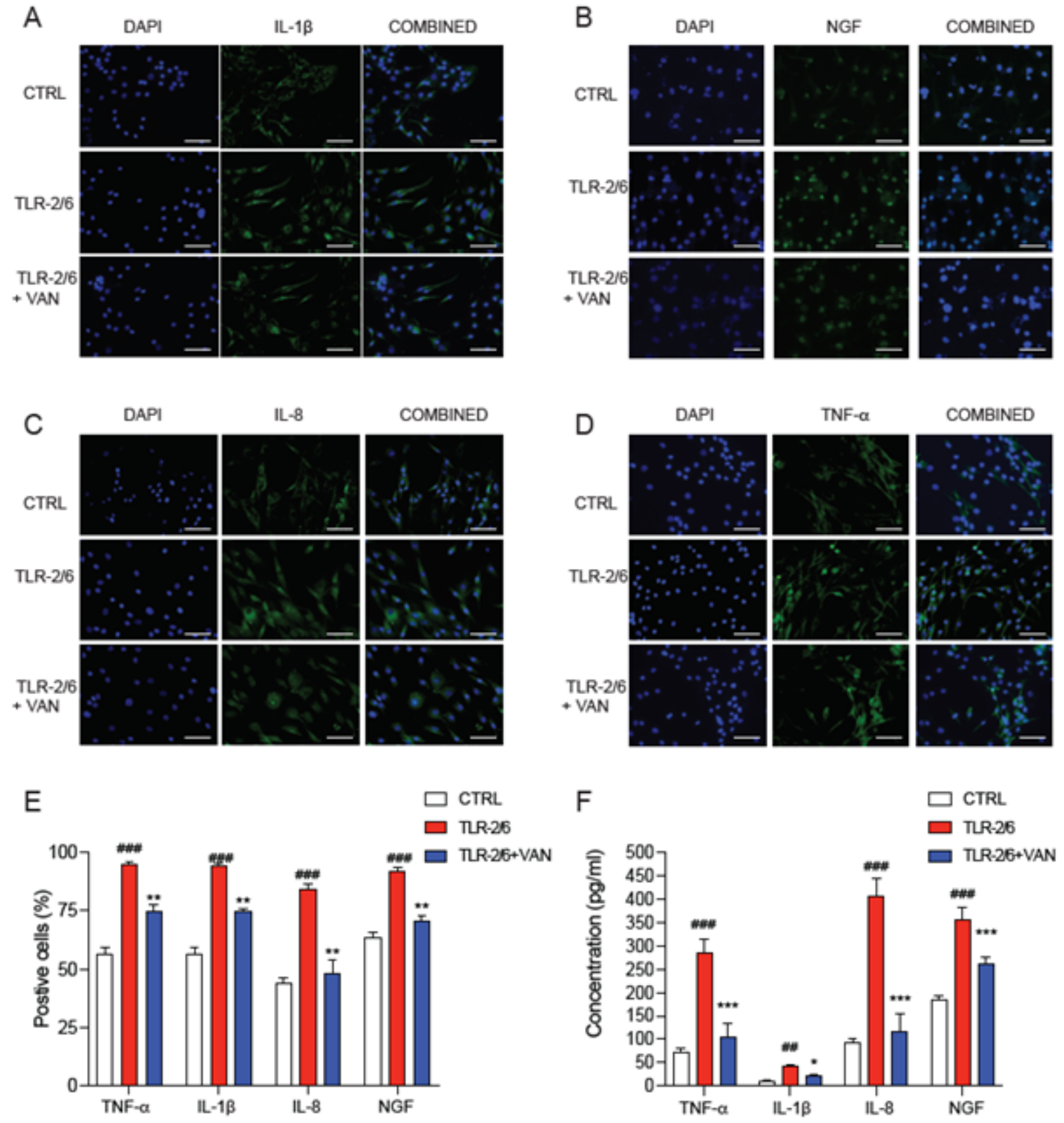

Figure 4 
o-Vanillin reduced the protein expression of SASP factors (IL-1 3, NGF, IL-8 and TNF-a) following TLR-2/6 activation of IVD cells from patients with back pain and IVD degeneration Disc cells from degenerate IVD were cultured for 48 hours with TLR-2/6 with o-Vanillin (TLR-2/6 + VAN) or without o-Vanillin (TLR-2/6) treatment for $6 \mathrm{~h}$ or no induction with TLR-2/6 (CTRL). (A-D) Using Immunocytochemistry, untreated and treated IVD cells were stained for DAPI and either (A) IL-1 $\beta$, (B) NGF, (C) IL-8 (D) TNF-a respectively. Scale Bars $=25 \mu \mathrm{m}$. (E) Quantification of the percentage of the cells that stained positive for IL-1 $\beta, N G F$, IL-8 and TNF-a when non-induced, treated with TLR-2/ 6 agonist or treated with TLR-2/ 6 agonist and o-Vanillin. $n=5(F)$ ELISAs were performed to measure the concentration of TNF- $a, I L-1 \beta$ and IL-8 in cell media and NGF from cell lysate in non-induced, TLR-2/ 6 agonist treated or the combined treatment TLR-2/6 agonist and o-Vanillin treated samples. Percentage of positive cells in $(E)$ were the average for $n=5$, . $\# p<0.05$, $\# \# p<0.01, \# \# \# p<0.001$ indicate significant difference between the TLR-2/6 agonist treated to the noninduced control and ${ }^{*} p<0.05,{ }^{*} p<0.01,{ }^{* \star} \mathrm{p}<0.001$ indicate significant difference between the tested groups (E-F) Mean \pm SD, statistical analysis was done using paired t-test.

A

DAPI

p16

TLR2

Merge

Enlarged
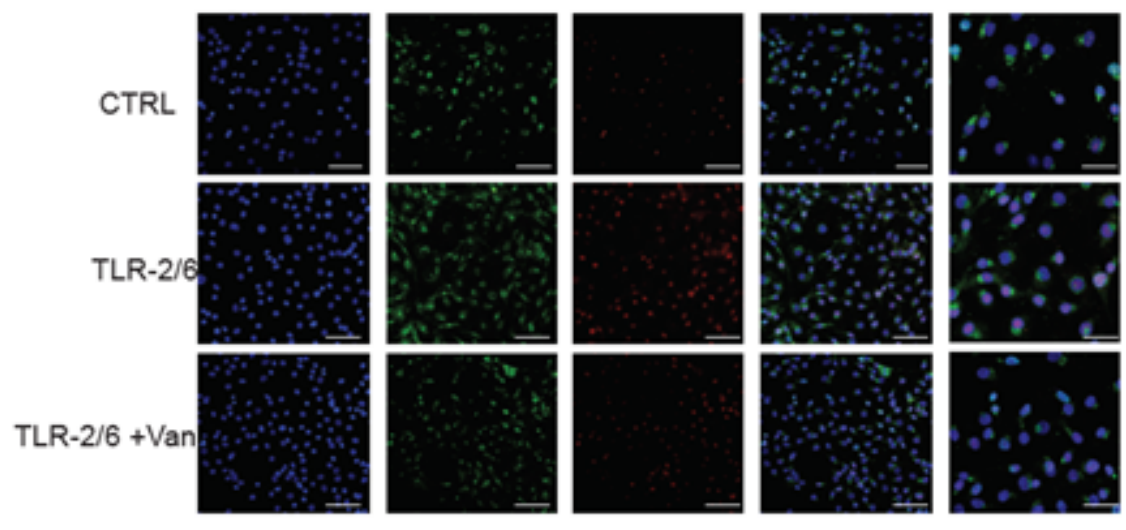

B

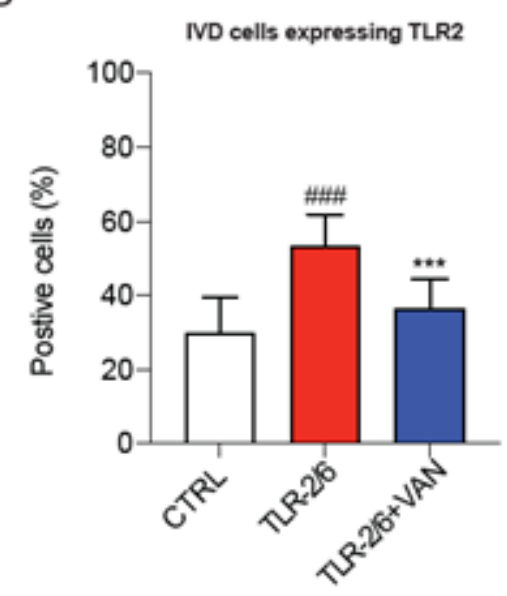

C

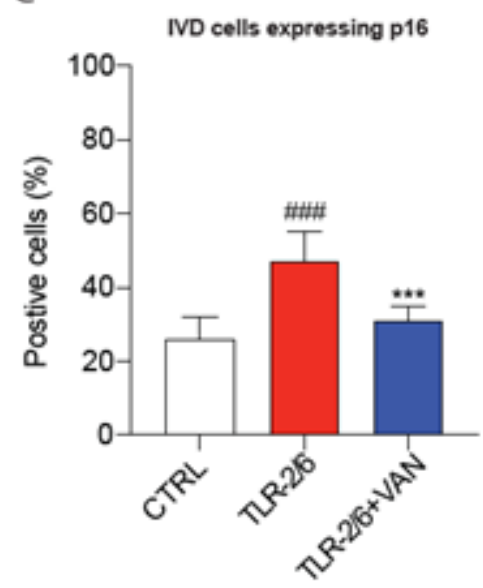

D

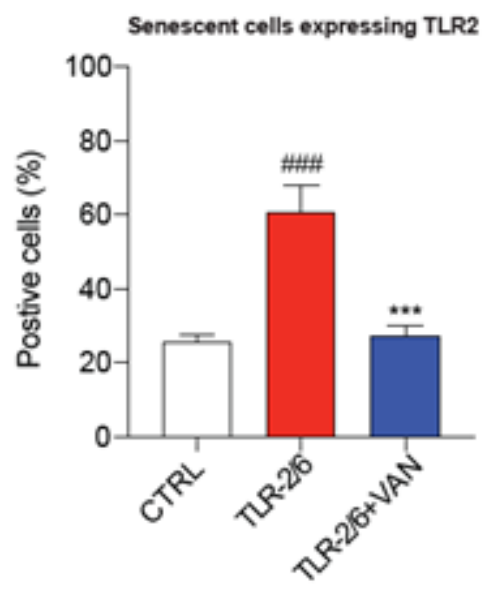

\section{Figure 5}

o-Vanillin reduced the number of cells co-expressing TLR-2 and p16ink4a in cells exposed to TLR-2/6 agonist Disc cells from degenerate IVDs were induced with TLR-2/ 6 agonist for 48 hours with (TLR$2 / 6+V A N$ ) or without (TLR-2/6) o-Vanillin treatment for 6 hours or no induction with TLR-2/ 6 agonist (CTRL). (A) Photomicrographs of IVD cells stained for DAPI (blue) and either p16ink4a (green), TLR-2 
(red), or the merge (p16ink4a and TLR-2) as revealed by Immunocytochemistry. DAPI, p16, TLR2 and merge images scale bars $=25 \mu \mathrm{m}$. Enlarged images scale bar: $10 \mu \mathrm{m}$. (B-D) Quantification of the percentage of IVD cells that stained positive for (B) TLR-2 (C) p16ink4a or (D) co-localized cell for TLR-2 and p16ink4a. Percentage of positive cells in (E) were the average for $n=5 . \# p<0.05, \# \# p<0.01$, \#\#\#p<0.001 indicate significant difference between the TLR-2/6 agonist treated to the non-induced control and ${ }^{*} p<0.05,{ }^{*} p<0.01,{ }^{* *} \mathrm{p}<0.001$ indicate significant difference between the TLR-2/ 6 agonist with o-Vanillin treated to the TLR-2/6 agonist treated. (B-D) Mean \pm SD, statistical analysis was done using paired t-test.

\section{Supplementary Files}

This is a list of supplementary files associated with this preprint. Click to download.

- SupplementaryTables.docx 